\title{
Life Cycle Assessment-based method of Excessive Commodity Packaging on Energy Conservation and Emissions Reduction
}

\author{
Si-ying Wang, Xi-chun Bao, Ning-ling Wang \\ School of Control and Computer Engineering, North China Electric Power University, Beijing, China \\ Email: 469276012@qq.com
}

Received March, 2013

\begin{abstract}
Based on a Life Cycle Assessment model, the effect of the whole life cycle of excessive commodity packaging on the environment was analyzed by eBalance Evaluation LCA software from production through circulation. The cost evaluation system and environment impact model of its three main processes, that is, material production, product machining and waste manufacturing, were established to identify the main environmental impact corresponding indicators and the influence on energy conservation and emissions reduction of excessive packaging life cycle. And packaging of moon-cakes was taken as an example to analyze the difference between the ordinary packaging and excessive packaging of moon-cakes in terms of life cycle assessment and costs analysis. Meanwhile some measures are put forward to conserve energy and reduce emissions.
\end{abstract}

Keywords: Energy Conservation and Emissions Reduction; Excessive Package; Life Cycle Assessment

\section{Introduction}

Nowadays, with the continuous development of the economy, people's living standards is gradually improving. Excessive packaging has become a serious social economic phenomenon. At present, there are lots of researches about the environmental impact of commodity packaging, and the typical model of LCA can be found in [1-3]. But in most researches, only the simplified mathematical models were used which can lead to subjectivity, striking differences in assessment and limited use as a role of guiding the practice. Based on a Life Cycle Assessment model, the effect of the whole life cycle of excessive commodity packaging on the environment was analyzed from production through circulation. The cost evaluation system and environment impact model of its three main processes, that is, material production, product machining and waste management, was established to identify the main environmental impact corresponding indicators and the influence on energy conservation and emissions reduction of excessive packaging life cycle.

\section{Overview of the Research Method}

\subsection{Life Cycle Assessment}

Life Cycle Assessment is a technique to assess environmental impacts associated with all the stages of a product's life from-cradle-to-grave. LCAs can help avoid a narrow outlook on environmental concerns by the following methods: Compiling an inventory of relevant energy and material inputs and environmental releases; evaluating the potential impacts associated with identified inputs and releases; interpreting the results to help make a more informed decision. The evaluation of this paper runs through the product, process and activities of the whole life cycle, including raw materials extraction and processing, product manufacturing, transportation and sales, product use, reuse and maintenance, waste cycle and final disposal.

\subsection{Technical Framework of Life Cycle Assessment}

According to the ISO 14040 and 14044 standards, a Life Cycle Assessment [4] is carried out in four distinct phases which are as follows and shown in Figure 1 :

- Goal and scope definition. An LCA starts with an explicit statement of the goal and scope of the study.

- Life Cycle Inventory (LCI). A flow model of the technical system is constructed by means of using data on inputs and outputs. Inventory flows include inputs of water, energy, and raw materials, and releases to air, land, and water.

- Life cycle impact assessment. This phase is aimed at evaluating the significance of potential environmental 
impacts

- Interpretation. The outcome of the interpretation phase is a set of conclusions and recommendations for the study.

\subsection{Environmental Impact Indicators}

This paper uses eBalance Evaluation LCA software to analyze and process each stage of material consumptions, energy consumption and emissions to the environment, and finally 11 types of Environmental Impact Indicators are concluded as follows: global warming potential (GWP), carbon dioxide emissions $\left(\mathrm{CO}_{2}\right)$, China's fossil energy consumption potential(CADP), primary energy consumption(PED), particulates(RI), industrial water consumption(lnWU), eutrophication potential(EP), $\mathrm{SO}_{2}$ emissions $\left(\mathrm{SO}_{2}\right), \quad \mathrm{NO}_{\mathrm{x}}$ emissions $\left(\mathrm{NO}_{\mathrm{x}}\right)$, Acidification potential (AP), Chemical oxygen demand (COD).

\section{Life Cycle Assessment Process of Excessive Commodity Packaging}

\subsection{Goal and Scope Definition}

This paper shall include all processes from raw materials to the final waste management. But because of the limitation of the time and funds, and the difficulty of data collection and data authenticity, usability, we give it a proper definition. Life cycle assessment process of excessive commodity packaging is as follows:

This process includes raw materials extraction and processing, transportation, packaging production and manufacturing, distribution sales, product use, waste management.

\subsection{Life Cycle Inventory (LCI)}

Because of the variety of commodity packaging materials, this article chooses the most representative corrugated paper for convenience. Allowing for complicated uncertainty factors in transport process, this paper takes no account of raw materials transportation and product distribution sales process. Furthermore there are only a few material consumptions and energy consumption which don't need maintenance during the use of product.

In conclusion, according to the Figure 2, we lay stress on its three main processes: material production, product machining and waste management.

The explanation of raw materials is as follows: corrugated paper is only used once; the data during waste disposal process refer to a wide range of statistical data in China, as is shown in Table $\mathbf{1 .}$

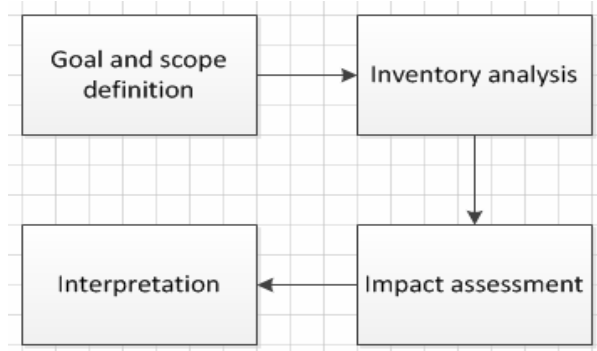

Figure 1. Technical framework of life cycle assessment.

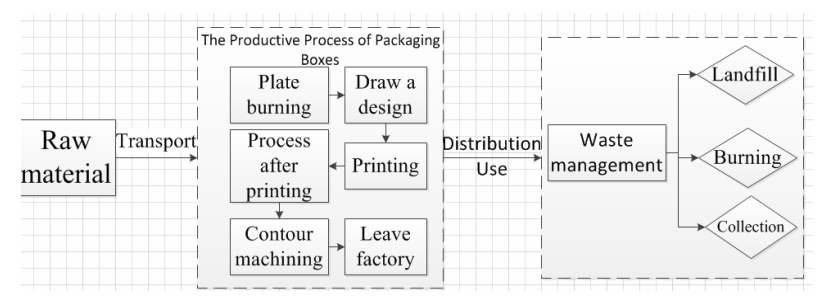

Figure 2. Life cycle process of excessive commodity packaging.

Table 1. Life Cycle Inventory of Processing Corrugated Paper [5]

\begin{tabular}{|c|c|c|}
\hline Corrugated Paper（1000kg） & Specific items & \\
\hline \multirow{4}{*}{ Raw material (kg) } & Wood & 300 \\
\hline & Waste paper & 1360 \\
\hline & Other chemical medicine & 4.25 \\
\hline & Energy consumption（kW.h） & 414 \\
\hline \multirow[t]{4}{*}{ Consumption (energy, steam) } & Consumption of steam（kg） & 1726 \\
\hline & Water consumption $\left(\mathrm{m}^{3}\right)$ & 41.8 \\
\hline & Bark or waste paper & 46 \\
\hline & Debris out of screening & 8 \\
\hline \multirow{4}{*}{$\begin{array}{l}\text { Waste emissions } \\
\text { (kg) }\end{array}$} & Debris out of desander & 14.5 \\
\hline & Deinked sludge & 31.5 \\
\hline & Biological sludge & 4.5 \\
\hline & amount of waste & 239.5 \\
\hline \multirow{4}{*}{ Wastewater emissions } & Effluent after treatment $\quad\left(\mathrm{m}^{3}\right)$ & 42 \\
\hline & Suspended solids SS（mg/L ） & 45.4 \\
\hline & Biological oxygen demand BOD(mg/L) & \\
\hline & Chemical oxygen demand COD(mg/L) & 638.9 \\
\hline \multirow{3}{*}{ Tailpipe emission } & $\mathrm{CO}_{2}(\mathrm{~kg})$ & 209 \\
\hline & $\mathrm{SO}_{2}(\mathrm{~kg})$ & 4.4 \\
\hline & $\mathrm{NO}_{\mathrm{X}}(\mathrm{kg})$ & 1.9 \\
\hline
\end{tabular}


In the production processing process, because there is no uniform mode in printing, proofing, processing and the situation is much more complicated, we only lay stress on the most representative printing process. Material flow in the process of printing is shown in Figure 3, and pollutant emission data list is shown in Table 2.

In the collection process, as shown in Figure 4, waste management can be divided into regeneration treatment, incineration power and landfill.

Considering that the finished product packing box may also contain other material auxiliary decoration materials, and no unified mode, so the packaging of goods will focus on the corrugated paper waste management, and Table 3 shows data:

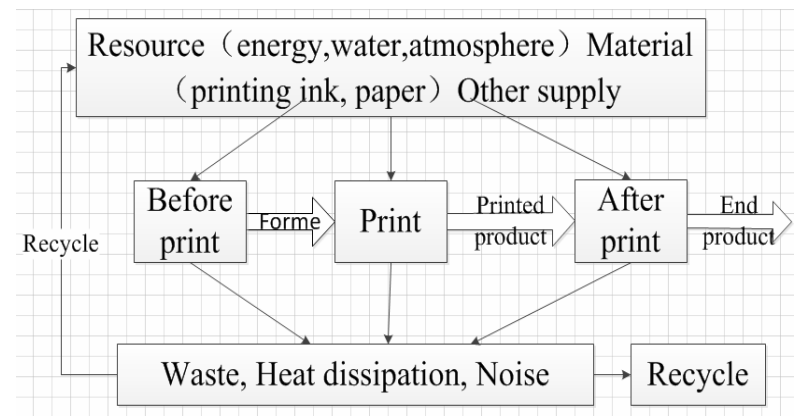

Figure 3. Material flow in the process of printing.

Table 2. Pollutant emission data list in the process of printing.

\begin{tabular}{ccc}
\hline Organics & $\begin{array}{c}\text { Emission concentration } \\
\left(\mathrm{mg} / \mathrm{m}^{3}\right)\end{array}$ & $\begin{array}{c}\text { Rate of emission } \\
(\mathrm{kg} / \mathrm{h})\end{array}$ \\
\hline Ethyl acetate & 150 & 12 \\
Methylbenzene & 60 & 12 \\
Butanone & 150 & 12 \\
Acetone & 150 & \\
Solvent & 2.33 \\
Consumption t/d & $\begin{array}{c}\text { (Printing machine daily } \\
\text { consumption) }\end{array}$ \\
\hline
\end{tabular}

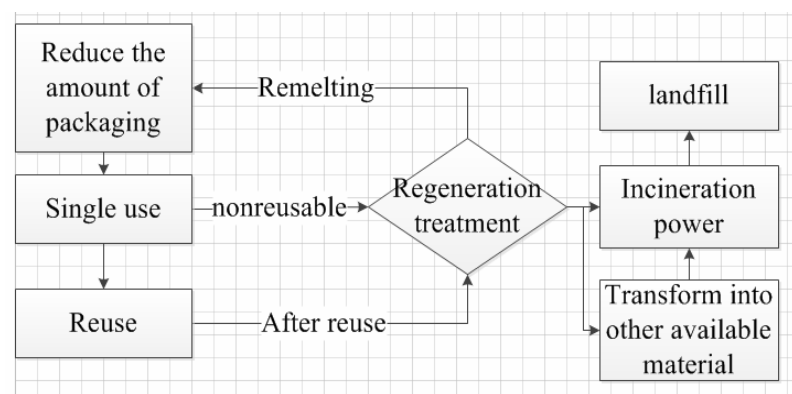

Figure 4. Waste manufacturing process.
Table 3. Corrugated paper waste management [1].

\begin{tabular}{ccc}
\hline Process & Index & Amount $\left(\mathrm{g} / \mathrm{m}^{2}\right)$ \\
\hline & waste incineration & 329.05 \\
Waste management & collection & 383.90 \\
& landfill & 438.74 \\
\hline
\end{tabular}

\subsection{Impact Assessment}

Using eBalance Evaluation software and its includible database, commodity packaging was analyzed from production through circulation. According to the analysis of results on common packing, a conclusion was drawn on the environment impact of excessive packaging qualitatively. Analysis results are shown below.

According to Figure 5, it's shown that CADP and COD are the principal aspects of environment impact in the proceeding of corrugated paper. And the consumption of fossil fuel increases because of the use of fuel and electricity. Chemical oxygen demand (COD) is mainly used to measure how much organic matter contains in the water .The more COD there is, the more serious the water pollution is by the organic matter.

The energy consumption in the proceeding abovementioned includes water, electricity and steam. Steam leakage occurs in the highest frequency, which will lead to the consumption of coal and electric power, so it is necessary to strengthen the prevention. Besides, the waste water and waste ink from printing machine and other equipment will cause great pollution to the atmosphere, water quality and soil, thus it is of great importance to do some relevant management well.

We can learn from the Figure 6 that there are two main causes including RI and CADP to the environment in the proceeding of packaging production. Compared with common packaging, excessive packaging will cause more great influence on the two aspects and other indexes such as acidification, eutrophication and $\mathrm{CO}_{2}$ emission and so on.

Aiming at the questions above, on the one hand we should choose the appropriate packing material according to the character of the inner commodity and pay less attention to pursue the gorgeous appearance. On the other hand, we should introduce advanced equipment actively, optimize the production process, try our best to reduce the use of raw materials and improve the strength and quality of packing.

When dealing with the same quantitative abandon carton, the environment impact of incineration, recycle and landfill treatment and the comparison of the three methods were shown in the Figures 7-10.

There are three main environment impact indicators in the incineration proceeding: $\mathrm{AP}, \mathrm{SO}_{2}$ and $\mathrm{RI}, \mathrm{CADP}$, 


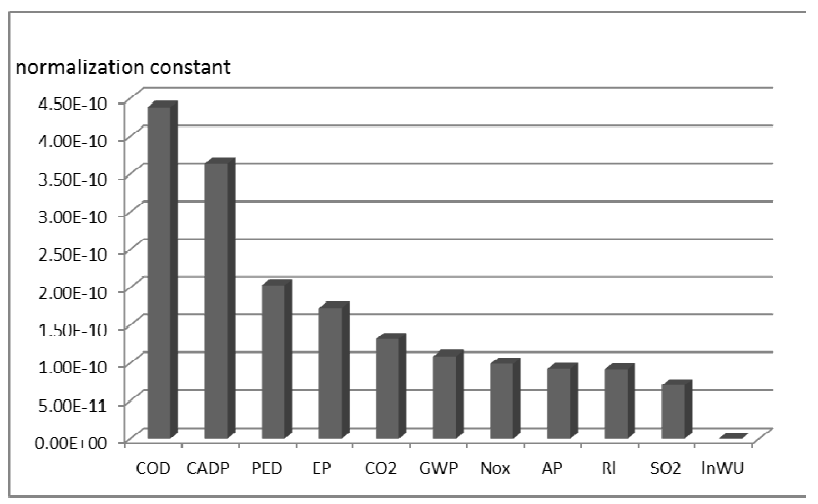

Figure 5. Environment impact on the manufacture of corrugated paper.

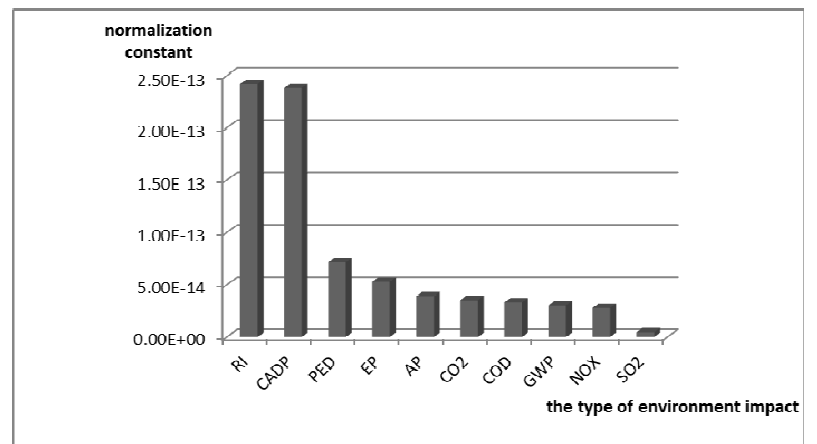

Figure 6. Environment impact on the production proceeding of packaging.

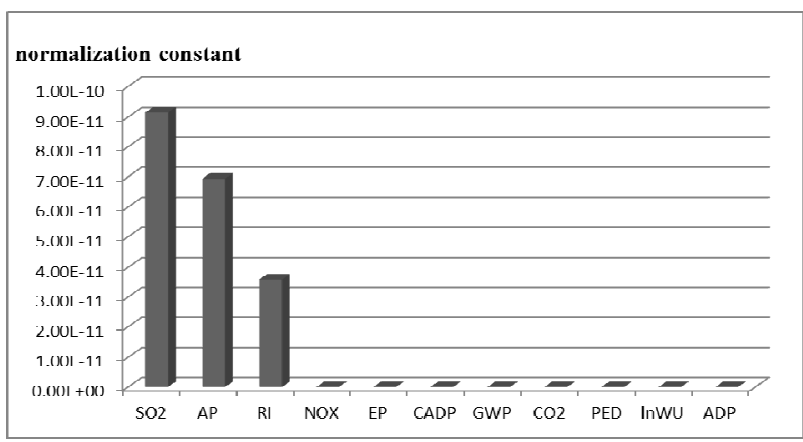

Figure 7. Environment impact of processing method of incineration power.

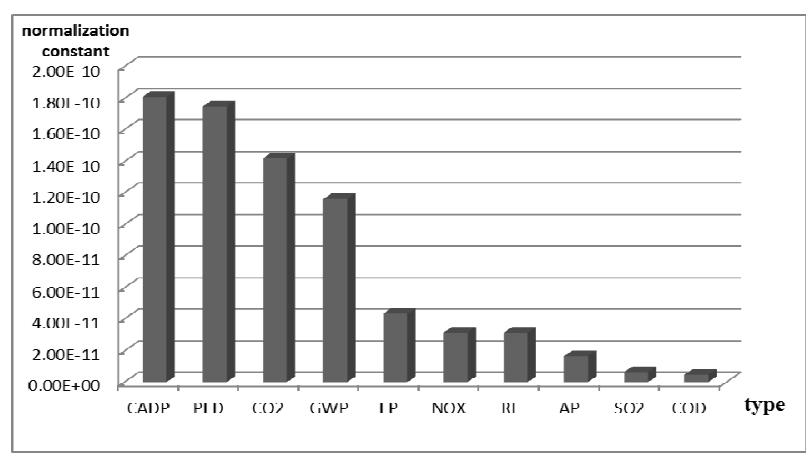

Figure 8. Environment impact of processing method of recycle.

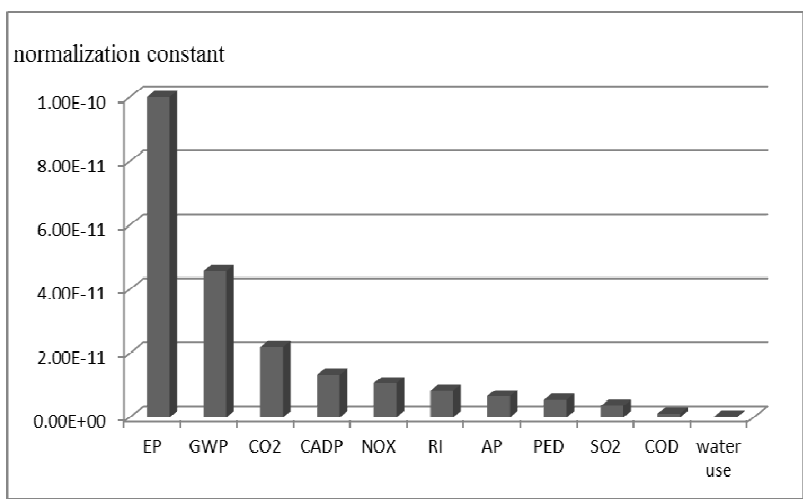

Figure 9. Environment impact of processing method of landfill treatment.

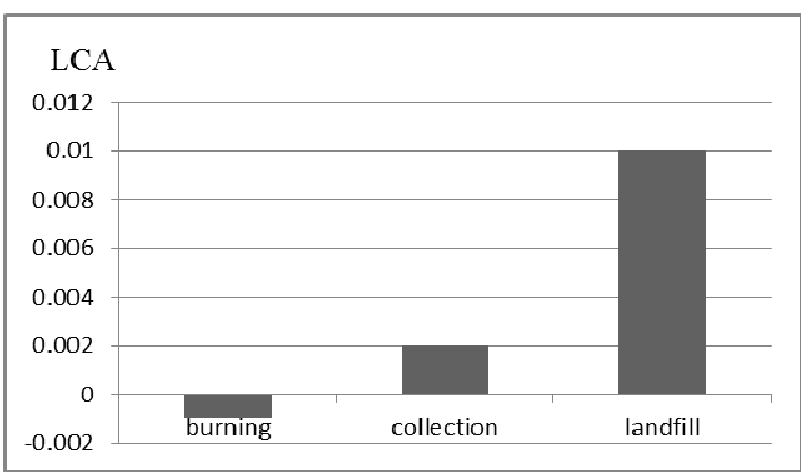

Figure 10. Environment impact of the three waste treatment methods.

PED, $\mathrm{CO}_{2}$ and GWP are the principal causes in the recycle proceeding. Recycling abandon carton to make pulp saves the production of raw materials. However, its energy dissipation has a negative impact on the global warming. In the proceeding of landfill treatment, EP and GWP play an important role.

Generally speaking, the environment influence of the three is successively increasing. Incineration power can reduce the pollution to the natural environment effectively. Landfill treatment own the low lost and require easier technology, however, considering that the decomposition of abandon carton will generate toxic substance, which will create terrible pollution to the atmosphere ,water and soil, so it is the last choose in the three treatment.

\section{Case study: LCA of Common Packaging and the Excessive Packaging about Moon-cake}

\subsection{Analysis of Energy Consumption and Emission of Moon-cake Carton}

In order to compare the environment impact on the two kinds of packaging quantitatively, packaging of mooncakes was taken as an example to analyze the difference 
between the ordinary packaging and excessive packaging of moon-cakes in terms of life cycle assessment and costs analysis. A model is set up to calculate the cost of packing. According to a formula:

The cost of material $=$ material cost per unit $*$ material quantity.

we can calculate the cost of two packaged form, and the results are shown in the Table 4.

We can learn that:

- Energy consumption of excessive packing is roughly 6 times as much as the ordinary packing; water consumption of excessive packing is 4 times as much as those of ordinary packing.

1. Wood consumption of excessive packing is about 4 times as much as those of ordinary packing. Consumption of Crude oil is 3 times as much as those of ordinary packing. Cast iron, limestone and other raw materials are not used in the ordinary packing.

2. Emissions of $\mathrm{CO}_{2}$ and $\mathrm{NO}_{\mathrm{x}}$ of over package are approximately 5 times as much as those of ordinary packing. Emissions of $\mathrm{SO}_{2}$ are 9 times as much as those of ordinary packing and emissions of HC are about 4 times as much as those of ordinary packing.

3. BOD and COD are the main water quality pollutant of excessive packing, which are about 4 times as much as those of ordinary packaging.

4. Off scum emissions of excessive packaging are about 72 times as much as those of ordinary packing. Dust capacity is about 27 times as much as those of ordinary packing.
The comparison of environment impact in the whole production proceeding of moon-cake packaging is shown in the Figure 11. The proportion of each cause to environment effect is listed from big to small, which are RI, lnWU, PED, $\mathrm{CO}_{2}$, GWP, EP and AP.

However, the environment effect created by the respiratory action of inorganic substance of excessive packaging is about 5 times as much as those of ordinary packaging. Industry water supply volume, PED and GWP are roughly 6 times as much as those of ordinary packing. AP and EP are about 5 times as much as those of ordinary packaging. Through the comparative results we can learn that excessive packaging will lead to more energy and resources consumption and thus have a harmful effect to the environment.

\section{Conclusions}

In this paper, we apply the procedure-based all-life cycle method to the section of raw material, product processing, product use and produce waste disposal for paper packaging to have a close analysis, and take the moon-cake paper packing for instance so as to imply that the damage caused by excess packing mainly attributes to the consuming of the fossil energy, the emissions of the respirable inorganics, and the climate change caused by the emission of $\mathrm{CO}_{2}$.

As for the problems arising from applying the all-life cycle method, which include the complexity of the sections and lack of the data in the product packing, further research is needed in the following aspects:

Table 4. Moon-cake inventory and cost analysis [6].

\begin{tabular}{|c|c|c|c|c|c|c|}
\hline \multicolumn{2}{|c|}{ Evaluation items } & $\begin{array}{l}\text { Excessive } \\
\text { packaging }\end{array}$ & $\begin{array}{c}\text { Ordinary } \\
\text { packaging }\end{array}$ & $\begin{array}{l}\text { Material } \\
\text { cost }\end{array}$ & $\begin{array}{l}\text { Over packing } \\
\text { cost/yuan }\end{array}$ & $\begin{array}{c}\text { Ordinary packing } \\
\text { cost/yuan }\end{array}$ \\
\hline \multicolumn{2}{|c|}{ Energy consumption/MJ } & 91.549 & 15.573 & & & \\
\hline \multicolumn{2}{|c|}{ Water consumption/kg } & 271.461 & 65.701 & 4.05yuan/t & 1.09 & 0.26 \\
\hline \multirow{4}{*}{$\begin{array}{l}\text { Main material } \\
\text { consumption/g }\end{array}$} & wood & 4773.693 & 1225.699 & 1700yuan/t & 8.12 & 2.08 \\
\hline & Crude & 326.096 & 106.045 & 619.2yuan /barrel & 1.27 & 0.41 \\
\hline & Cast iron & 657.164 & / & 2555yuan /t & 1.68 & 0 \\
\hline & limestone & 744.785 & I & $700 y u a n / \mathrm{m}^{3}$ & 1.93 & 0 \\
\hline \multirow{4}{*}{ Gases emissions/g } & $\mathrm{CO} 2$ & 10044.398 & 1836.405 & \multirow{8}{*}{ total } & \multirow{8}{*}{14.09} & \multirow{8}{*}{2.75} \\
\hline & $\mathrm{SO}_{\mathrm{x}}$ & 37.294 & 4.14 & & & \\
\hline & $\mathrm{NO}_{\mathrm{x}}$ & 31.306 & 5.971 & & & \\
\hline & $\mathrm{HC}$ & 7.841 & 2.172 & & & \\
\hline \multirow{2}{*}{$\begin{array}{c}\text { Water quality } \\
\text { pollutant/g }\end{array}$} & BOD & 5.591 & 1.415 & & & \\
\hline & COD & 14.85 & 3.76 & & & \\
\hline \multirow{2}{*}{ Solid waste/g } & offscum & 1837.368 & 25.663 & & & \\
\hline & stive & 151.291 & 5.661 & & & \\
\hline
\end{tabular}




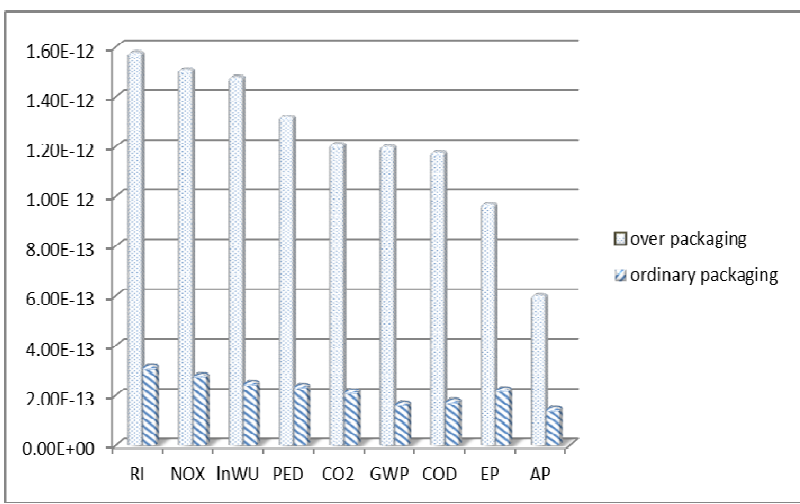

Figure 11. The environment impact on the whole production proceeding of moon-cake.

1) Collect more raw data and perfect data for modeling. The concrete actions include the collection of the data from the production of packing boxes, plate-making, print, surface treatment, and so on.

2) More detailed analysis to the procedure of the alllife cycle method. Improve the integrity of analysis in life cycle of the boxes-packing, especially in transporting section, Sales and Distribution section, and the using section. Build a model linked to the economic efficiency of every section of the excess packing and the influence of the climate, so that we'll get to the goal of evaluating and optimizing the all-life cycle method.

\section{REFERENCES}

[1] J. Y. Liu, Q. J. Yang and X. M. Han, "Life Cycle Assessment of Environmental Impact of Corrugated Boxes," Research of Environment Science, Vol. 21, No. 6, 2008.

[2] R. L. Guo and S. S. Zhou, "Evaluation System of Packing Material Based on LCA,” 2007.

[3] C. M. Lu, "Research of Design of Green Product in the Direction If LCA,” Vol. 24, No. 4, 2006.

[4] F. Y. Li, J. F. Li and L. J. Yan, "Present State and Perspectives of Green Design of Product Based on LCA," Modern Manufacturing Technology, Vol. 8-14, 2006.

[5] F. Li, "Life Circle Evaluation of Environment Impact Based on a Paper-making Factory,” 2008.

[6] L. Fang, X. Q. Ma, Z. L. Zhao and H. B. Li, "Evaluation on Packaging of Moon Cake Based on LCA,” Packing Engineering, Vol. 27, No. 1, 2006. 